\title{
My Role and Its Virtues
}

\author{
Richard Paul Hamilton ${ }^{1}$
}

Published online: 21 November 2016

(C) Springer Science+Business Media Dordrecht 2016

It has become something of a cliché to introduce any anthology of virtue ethics with a brief excursus on the Renaissance of virtue ethics, beginning with G.E.M Anscombe's 1958 paper Modern Moral Philosophy. ${ }^{1}$ Since it is almost sixty years since the publication of Anscombe's essay and thirty years since the work of Philippa Foot and Rosalind Hursthouse this assertion of virtue ethics' status as "new kid on the block" is starting to sound a little disingenuous. Virtue ethics is now well established and, despite earlier worries expressed by critics that it provided no practical guidance, this is nowhere more the case than in professional and applied ethics. There are good reasons for this. Virtue ethics offers an attractive alternative to the quasi-legalistic model that still dominates these fields. If Lord Moulton was correct to describe ethics as "obedience to the unenforceable" we begin to see why many professionals faced with pressing moral and ethical dilemmas find the quasilegalistic model so dissatisfying. The complex moral predicaments that professional life throws up, pose in stark relief the conflict between one's status qua professional and one's broader status as a reflective human being concerned that one's life hangs together in a coherent way. If we identify too rigidly with our role we may end up committing gross injustice, particular in situations of institutional failure. If, on the other hand, we wear our role too lightly, we might be vulnerable to accusations of insincerity or disloyalty to one's profession. This in a nutshell is the problem of role ethics as it presents itself in the context of virtue ethical theory. All of the essays in this special edition touch on this topic and contribute to moving the debate forward in interesting ways.

\footnotetext{
1 Anscombe, G.E.M. (1958). 'Modern Moral Philosophy', Philosophy, 33(124), pp. 1-19.

Richard Paul Hamilton

Richard.Hamilton@nd.edu.au

1 The University of Notre Dame Australia, Fremantle, WA, Australia
} 
Christine Swanton and Tim Dare are colleagues and the opening pair of essays continue an ongoing debate between them about role ethics. Dare has famously defended a version of what he calls "The Standard Conception" of a lawyer's role in which a lawyer is permitted to violate elements of common morality in pursuit of a vigorous legal defence. Swanton suggests that what she calls "Orthodox Virtue Ethics" would dispute this but is thereby incapable of developing a proper role ethics. She argues that any truly satisfying Virtue Ethical approach to role ethics must proceed from the recognition of professional expertise and that this enables us to understand why things like the Standard Conception are morally defensible and in accord with the best thinking on virtue. Dare's own contribution to this edition brings his considerable analytic skills to bear on the question of how precisely roles confer normative status and while not explicitly written from a virtue theoretic perspective has much to contribute to the development of a virtue ethical account of roles.

Anne Baril's essay continues this theme by distinguishing a specifically ethical conception of roles in contrast to a sociological or social psychological conception. She aims to clarify the precise sense in which roles can be seen as ethically important and thereby be seen as contributing to a life well lived. My own contribution argues along similar lines that a specific suite of personal and professional virtues come together to constitute an ideal type which I refer to as the "wholehearted professional". Drawing upon Harry Frankfurt's idea of wholeheartedness I argue that we should integrate the idea of professional formation within the broader context of what John McDowell has called "Second Nature" 2 . It turns out that the formation and maintenance of Second Nature is not an all or nothing endeavour completed in adolescence but rather a lifelong pursuit in which professional development can be seen as a central part of a good life.

Michael Levine and Damian Cox turn to a specific institutional setting which is all too familiar to most readers of this journal namely the modern corporatised university. Despite the jargon of "excellence" currently in vogue, the entire institutional setting seems geared to frustrating many of the characteristic virtues of academic life and actively promoting vices such as hubris and dishonesty.

Justin Oakley has been a key figure in the development of a specifically virtue based approach to professional ethics. His essay discusses the application of virtue ethics to public policy using medicine as a case study. His analysis of the influence of pharmaceutical companies on doctors' prescribing behaviour brings out nicely the contribution that a virtue based approach can bring to clinical ethics as it captures ethical issues that other normative theories tend to neglect but which bear directly on doctors own self-conception. He concludes by making some powerful points about the need for regulatory frameworks to consider the virtues.

Nafsika Athanassoulis raises a topic which has not been dealt with sufficiently in recent years but which has deep contemporary relevance following the Great Financial Crisis of 2008 and its aftermath. She does so in the context of revisiting an Ancient Greek topic which is the controversial virtue of magnificence. She discusses whether a successful business person or one who has inherited wealth can navigate

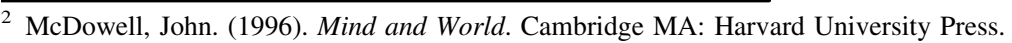


some of the ethical challenges that great wealth poses by the proper exercise of this classical virtue.

The final essay in the edition draws together several of the major themes and in addition brings to bear an interesting cross-cultural perspective. Cheryl Cottine discusses the development of role ethics in the context of classical Chinese thought and in particular the Confucian literature on role modelling. This analysis enables us to see both the deep commonalities between Ancient Greek and Chinese thought but also illuminating differences.

This special edition constitutes a significant contribution to the literature on role ethics and to virtue ethics more broadly. A common objection to virtue ethics is the so-called Situationist Critique which claims (based upon questionable readings of even more questionable research in Social Psychology) that virtue ethics fails to attend to the effects of concrete settings on moral agents. The papers collected here provide a robust practical rebuttal of this charge.

It has been a pleasure to work with all the contributors and I would like to thank them for their prompt responses to editorial queries. I would also like to thank Laura de Lange and Blair Vidakovich for their technical assistance in producing this special edition. 